\title{
Üretim sırasında anatomik olarak şekillendirilmiş topuk kemiği plağı
}

\author{
Calcaneal plate anatomically shaped during manufacture \\ İran Esenkaya \\ Ortopedi ve Travmatoloji Uzmanı, Emekli Öğretim Üyesi \\ SANTE Tıp Merkezi, Ortopedi ve Travmatoloji Kliniği, İstanbul
}

Buluş, tıp alanında ve topuk kemiği (kalkaneus) kaynakIı kırıklarda kullanılmak üzere, sağ ve sol topuk kemiği için ayrı ayrı ve farklı topuk kemikleri için farklı ebatlarda oluşturulan ve topuk kemiğinin dış duvarının anatomik yapısına uyum sağlayacak şekilde girinti, çıkıntı ve eğimlere sahip en az bir gövdeden ve bahsedilen topuk kemiğine sabitlenmesini sağlamak üzere enine açılmış en az bir bağlantı deliğinden meydana gelen topuk kemiği plağı ile ilgilidir. Konuyla ilgili faydalı model dosyası paylaşılmıştır. Yapılan klinik çalışmalar ile, eklem içi parçalı kalkaneus kırıklarının cerrahi tedavisinde kalkaneusun dış yüzey anatomik yapısına uygun olarak üretim aşamasında şekillendirilmiş çerçeve plak-vida uygulaması ile yeterli stabilite ile klinik ve radyolojik olarak tatmin edici sonuçlar elde edildiği gösterilmiştir.

Anahtar sözcülkler: faydalı model; kalkaneus; kırık; tespit; plak; lateral çerçeve plak

\section{T. C. Türk Patent Enstitüsü'ne Faydalı Model Belgesi için Başvuru Bilgileri ${ }^{[1]}$}

Başvuru bilgileri Tablo 1'de gösterilmiştir. ${ }^{[1]}$

Tablo 1. Başvuru bilgileri ${ }^{[1]}$

$\begin{aligned} \text { Başvuru numarası: } & 2010 / 01325 \\ \text { Başvuru tarihi: } & 23.02 .2010 \\ \text { Başvuru şekli: } & \text { Ulusal başvuru } \\ \text { Evrak numarası: } & 2010-\mathrm{G}-41918 \\ \text { Evrak tarihi: } & 23.02 .2010 \\ \text { Tescil numarası: } & 201001325 \\ \text { Tescil tarihi: } & 21.10 .2010 \\ \text { Koruma tipi: } & \text { Faydalı model } \\ \text { Başvuru sahipleri: } & \text { Irfan Esenkaya } \\ & \text { TIPSAN Tıbbi Aletler Sanayi ve } \\ & \text { Ticaret Anonim Şirketi } \\ \text { Buluş sahipleri: } & \text { İrfan Esenkaya }\end{aligned}$

The invention is designed to be used in the medical field and in fractures originating from the calcaneus, at least for the right and left calcaneus, which are formed in different sizes for different calcaneus, and have indentations, protrusions and slopes in a way to adapt to the anatomical structure of the outer (lateral) wall of the calcaneus. It relates to the calcaneal plate consisting of a body and at least one connection hole transversely opened to provide fixation to the said calcaneus. The utility model file on the subject has been shared. With clinical studies, it has been shown that in the surgical treatment of displaced intraarticular calcaneus fractures, a frame plate-screw application shaped in accordance with the anatomical structure of the outer surface of the calcaneus at the manufacture stage provides satisfactory clinical and radiological results with sufficient stability. Key words: utility model; calcaneus; fracture; fixation; plate; lateral frame plate

\section{FAYDALI MODEL BELGESI - No: TR 2010 01325[1] TARIFNAME[1]}

\section{Teknik Alan ${ }^{[1]}$}

"Buluş, tıp alanında, topuk kemiği (kalkaneus) kırıklarında kullanılmak üzere oluşturulan ve kemiğin dă̆ıImasını engelleyen ve toparlanmasını sağlayan bir plak ile ilgilidir. ${ }^{[1]}$

Buluş, topuk kemiğinin dış yüzünün düzensiz ve eğimli anatomik şekline uyum sağlayacak şekilde, bu bölgenin anatomik yapısı göz önüne alınarak imalat (üretim) safhasında şekil verilmiş, sağ ve sol topuk kemiği (kalkaneus) için ayrı ayrı olmak üzere her bir taraf için en az iki farklı boyutta (ebatta) oluşturulan plaklar ile ilgilidir. ${ }^{[1]}$ ”

\section{Tekniğin Bilinen Durumu[1]}

“Topuk kemiği (kalkaneus) farklı yapısı ve şekli ile vücut ağırı̆̆ını zemine aktarmakta ve bacak kasları için de bir

- İletişim adresi: Prof. Dr. İrfan Esenkaya, SANTE Tıp Merkezi, Ortopedi ve Travmatoloji Kliniği, Kalamış, Kadıköy, İstanbul Tel: 0532 - 3218681 e-posta: iesenkaya@hotmail.com ORCID iD: 0000-0002-7321-0012

- Gelișt tarihi: 7 Kasım $2020 \quad$ Kabul tarihi: 17 Kasım 2020 
kaldıraç görevi görmektedir. Kemik yapının içerisindeki trabeküler ă̆ yapısı, kemiğin karşılaştığı yüklenme ve gerilmelere karşı direnme gücü sağlamaktadır. Topuk kemig̈inin çevresi değişik kalınlıkta kortikal yapıdaki kemik duvar ile çevrili olup yoğun kansellöz (süngerimsi) kemik dokudan oluşur. Kortikal kemik yapısı, özellikle dış (lateral) duvarda incedir. Bu özellik de, kalkaneus kırıklarında dış duvarın yüklenmelere karşı koyamadan parçalanmasına neden olmaktadır. ${ }^{[1]}$

Topuk kemiği, ayaktaki tarsal (ayak bileğine ait) kemikler içerisinde en büyü̈̆̈̈ olup özel yapısı ile hem kuvvet nakli sağlar, hem de bükü̈cü (fleksör) kaslar için kaldıraç kolu görevi üstlenir. Topuk kemiğinin üst yüzü, ön ve arka olmak üzere iki parça şeklinde değerlendirilir. Arka bölümü hafifpürtüklü ve konveks bir çıkıntı şeklindedir. Ön bölümde ise, kalkaneusun talus ile oluşturduğu üç önemli eklem yüzü bulunmaktadır. Вu üç eklem yüzü, talustaki karşıtları ile birlikte subtalar eklemi oluşturur. Topuk kemiğinin alt yüzünde eklem yüzü bulunmamaktadır. Arka tarafta tuber kalkanei olarak isimlendirilen ve tendonların tutunduğu bir çıkıntı bulunur. Alt kısmı tuber kalkaneinin devamı şeklindedir. Aşil tendonu, kalkaneusun arka yüzündeki bu bölümün 1/3’lük bölümüne tutunmaktadir. ${ }^{[1]}$

Topuk kemiği dış yüzü ise geniştir ve nispeten pürüzsüzdür.

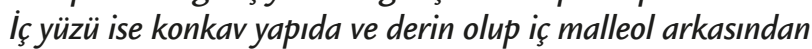
gelen damar, sinir ve tendonlar bu bölümden geçerek ayak tabanına doğru ilerlerler. Topuk kemiği ön tarafta küboid kemikle eklemleşir. ${ }^{[1]}$

Tekniğin bilinen durumunda uygulanan plaklar düz olarak imal edildikleri için ameliyat esnasında şekillendirilmek zorundadır. Kırığın tespiti için düz şekillendirilebilir rekonstrüksiyon plakları kullanılabildiği gibi "T", " $L$ " ve " $H$ ” şeklindeki rekonstrüksiyon plakları ile günümüzde düşük profilli kilitli anatomik plaklar da kullanılmaktadır. Bunun için kırık bölgesi tam olarak açılarak anatomiye uygun plak şekillendirilir. Ancak ameliyat esnasında hastanın kemik yapısına göre cerrah tarafindan şekillendirilen düz plaklarda, kontrolsüz ve arzu edilmeyen plak-vida deliği bozulmaları meydana gelmektedir. Düz plağı eğme esnasında üzerindeki kaplama yapısına istenmeyen zararlar verilebilmektedir ${ }^{[1]}$.

Bütün bu olumsuzluklardan dolayı, anatomik olarak topuk kemiği ile uyumlu plak ihtiyacı doğmuştur. ${ }^{[1] ”}$

\section{Buluşun Kısa Açıklaması ${ }^{[1]}$}

"Mevcut durumlardan esinlenerek oluşturulan ve yukarıda belirtilen olumsuzlukların üstesinden gelmek üzere, buluşun amaçlari ${ }^{[1]}$;

- Sağ ve sol topuk kemiği (kalkaneus) dış yüzlerine uyum sağlayacak şekilde üretim aşamasında şekillendirilerek, bu bölge kırıklarında bozulan kemik bütünlüğ̈̈nün tekrar oluşturulabilmesi (anatomik yenileme) ve yeterli sıkılıkta bir tespit sağlanabilmesidir.
- Stabil bir kırık tespiti sağlanarak, ameliyat sonrası erken dönemde ayak bileği eklemi hareketlerine başlanması ve alçılı tespite gerek kalmaksızın kontrollü olarak ayağa kalkarak (üzerine basmadan, yük vermeden) koltuk değnekleriyle dolaşma imkânının sağlanmasıdır.

- Ameliyat esnasında hastanın kemik yapısına göre cerrah tarafindan şekillendirilen düz plaklardaki kontrolsüz ve arzu edilmeyen plak-vida deliği bozulmalarını ve düz plağı eğme esnasında üzerindeki kaplama yapısında oluşan istenmeyen zararları engellemektir.

- Bölgenin anatomik yapısına uygun olarak önceden şekillendirilmesi sayesinde, kırık parçaların çerçeve şeklindeki plak üzerindeki vida deliklerinden uygulanan vidalara tespit edilerek arzu edilen anatomik bütünlüğ̈̈n elde edilmesidir.

- Farklı boy ve ebatlarda oluşturulması sayesinde, farklı büyüklükteki topuk kemiğine sahip hastalara da, ameliyat esnasında şekillendirme işlemi gerekmeden kullanılan plak sunmaktır.

Buluşun yapısal ve karakteristik özellikleri ile tüm avantajları aşağıda verilen şekiller ve bu şekillere atıflar yapmak suretiyle yazılan detaylı açıklama sayesinde daha net olarak anlaşılacaktır. Ve bu nedenle değerlendirmenin de bu şekiller ve detaylı açıklamalar göz önüne alınarak yapılması gerekmektedir. ${ }^{[1]}$ ”

\section{Buluşun Detaylı Açıklaması [1]}

"Şekillerdeki (parçaların) referans numaraları: (100) Topuk kemiği (kalkaneus) plağı, (110) Gövde, (111) Çerçeve, (112) Bağlantı deliği kolu ve (120) Bağlantı deliği. [1]”

"Çizimlerin mutlaka ölçeklendirilmesi gerekmemektedir ve mevcut buluşu anlayabilmek için gerekli olmayan detaylar ihmal edilmiş olabilmektedir. Bundan başka en azından büyük ölçüde özdeş işlevleri olan elemanlar, aynı numara ile gösterilmektedir. ${ }^{[1] ”}$

"Bu detaylı açıklamada, buluş konusu anatomik topuk kemiği plağııın (100) tercih edilen yapılanmaları, sadece konunun daha iyi anlaşılmasına yönelik olarak ve hiçbir sınırlayıcı etki oluşturmayacak şekilde açıklanmaktadır. ${ }^{[1]}$

Buluş, tıp alanında ve topuk kemiği (kalkaneus) kaynaklı kırıklarda kullanılmak üzere, să̆ ve sol topuk kemiği için ayrı ayrı ve farklı ebatlardaki topuk kemikleri için farklı ebatlarda oluşturulan ve topuk kemiğinin dış duvarının anatomik yapısına uyum sağlayacak şekilde girinti, çıkıntı ve eğimlere sahip en az bir gövdeden (110) ve bahsedilen topuk kemiğine sabitlenmesini sağlamak üzere enine açılmış en az bir bağlantı deliğinden (120) meydana gelen topuk kemiği (kalkaneus) plağı (100) ile ilgilidir. ${ }^{[1]}$

Buluşun tercih edilen yapılanması, tek sıra ve seri halde oluşturulan bağlantı deliklerine (120) sahip bir çerçeve (111) ve bunun içinde kalacak şekilde üç kol (112) ile 
bahsedilen çerçeveye (111) sabitlenen en az bir bağlantı deliği (120) içeren gövdeden (110) oluşmaktadır. ${ }^{[1]}$

Şekil 1.a ve 2.a'da sunulduğu gibi buluş, sağ topuk kemiğini, ayak dış tarafina bakan yüzünden ayak arkasına doğru geniş bir alanı, ayak ucuna doğru ise dar bir alanı kavrayacak şekilde oluşturulmaktadır. ${ }^{[1]}$

Şekil 1.b-d'de belirtildiği gibi, birçok girinti çıkıntı şeklinde radyuslu yüzeylere sahip topuk kemiğini kavrayabilmek için, buluş da aynı şekilde kemiğin anatomik yapısına uygun girinti ve çıkıntılara sahiptir. Kemiğin arka taraftaki geniş alanının ortasındaki girintiye de sabitlenebilmek için, bahsedilen çerçeveye (111) üç kol (112) ile bağlanan bir adet bağlantı deliği (120) oluşturulmaktadır. Bahsedilen kol (112) sayısı ihtiyaca göre artırılabilir ya da azaltılabilir. Ayrıca, bahsedilen tek bağlantı deliği (120) de, yine isteğe ve ihtiyaca bağı olarak birden fazla olarak oluşturulabilmektedir. ${ }^{[1]}$

Bahsedilen çerçeve (111) üzerinde, seri şekilde oluşturulmuş, tercihan ondört bağlantı deliği (120) bulunmaktadır. Bahsedilen merkezdeki delik (120) ile birlikte, bağlantı deliği (120) sayısı onbeşi bulmaktadır. Ancak plağın (100) ebatlarına ve ihtiyaca göre bu sayı değisstirilebilmektedir. ${ }^{[1]}$

Buluşu oluşturan bahsedilen çerçevenin (111) iç boşluğu, yine bahsedilen üç kol (112) ile üç küçük boşluğa bölünmektedir. Ihtiyaca göre, farklı ebatta plak (100) elde etmek amacıyla, bahsedilen boşluklardan ayakucuna yakın olan boşluk, enine geniş ya da dar olarak oluşturulmaktadır. Şekil 1 bu boşluğun geniş oluşturulduğu versiyonu, Şekil 2 ise dar versiyonu örneklemektedir. Aynı şekilde diğer boşlukların alanları ile de oynanarak, plak (100) ebatları değiş̧tirilebilir. ${ }^{[1]}$

Sol ayağa takılan plak (100) ise, săg ayak topuk plağının (100) ayna görüntüsü olarak oluşturulmaktadır. Şekil 3, sol tarafa ait plağın (100) geniş olan örneğini sunarken, Şekil 4 ise dar olan örneğini göstermektedir. ${ }^{[1]}$

Plak (100), topuk kemiğine monte (tespit) edilmek istendiğinde, bahsedildiği gibi kemiğin ayak dışına bakan yüzüne konumlandırılmaktadır. Buluş anatomik yapısı gereği uygun boyutta (ebatta) seçildiği sürece, kemiğe tam oturmaktadır. Yerleştirilen plak (100), bağlantı deliklerinden (120) geçirilerek kemiğe sabitlenen vidalar aracılığı ile monte edilmiş olmaktadır. Bahsedilen vidalar, bağlantı deliği (120) çaplarına uyumlu mini kortikal veya mini spongioz vidalardır. ${ }^{[1]}$

Plak (100) isteğe göre kilitli ya da kilitsiz olarak oluşturulabilmektedir. Yani vida başları, bağlantı deliklerine (120) açılan yivlere tutunabilir olarak oluşturulup, tek yönde ilerlemesi sağlanarak kilitli bir plak (100) ya da bahsedilen yivler oluşturulmayarak, vidanın istenilen yöne yönlendirilmesini sağlayıp kilitsiz plak (100) elde etmek mümkündür. Tercih edilen uygulamada, kilitsiz plak (100) kullanılmaktadır. ${ }^{[1]}$

Bahsedilen plaklar (100) ve dolayısıla uygulanacak vidalar, çelik malzemeden elde edilebileceği gibi, istendiği takdirde aynı vasıftaki titanyum gibi malzemelerden de üretilebilir. ${ }^{[1]}$ ”
Buluşun Açıklamasına Yardımcı Olacak Şekiller ${ }^{[1]}$

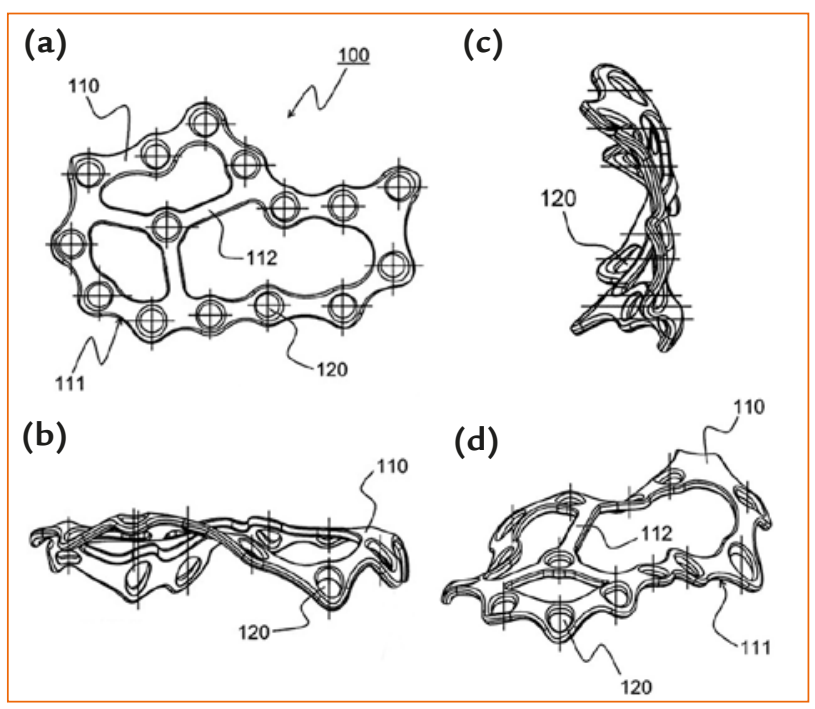

Şekil 1. a-d. Geniş ebatlı sağ topuk kemiği plağının önden (a), alttan (b), soldan (c) ve perspektif (d) görünümleri. ${ }^{[1]}$

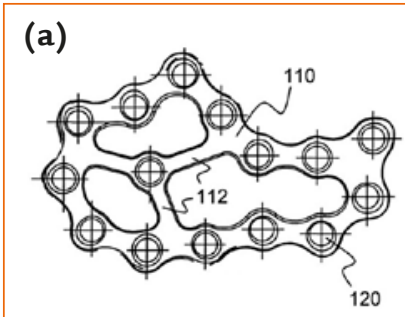

(c)
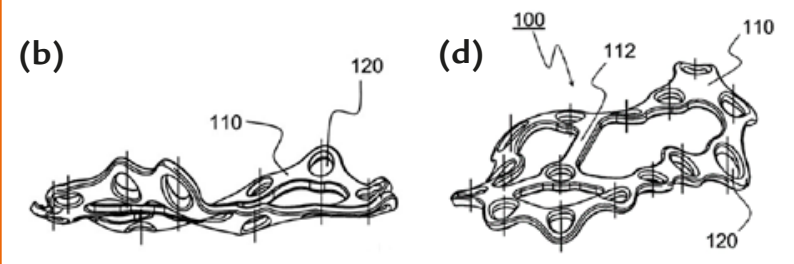

Şekil 2. a-d. Dar ebatlı sağ topuk kemiği plağının önden (a), alttan (b), soldan (c) ve perspektif (d) görünümleri.. ${ }^{[1]}$

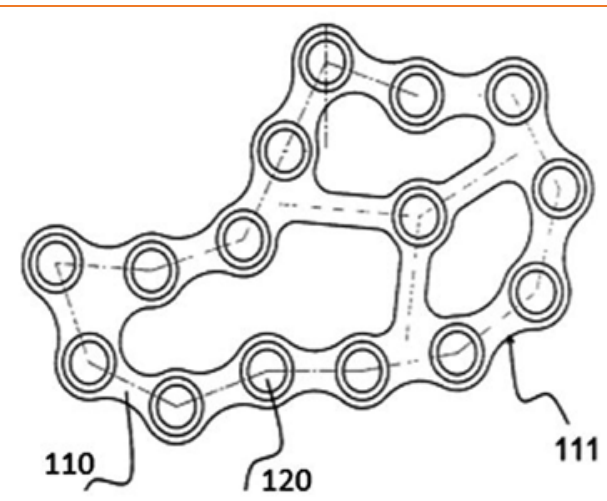

Şekil 3. Geniş ebatlı sol topuk kemiği plağının önden görünümü. [1] 


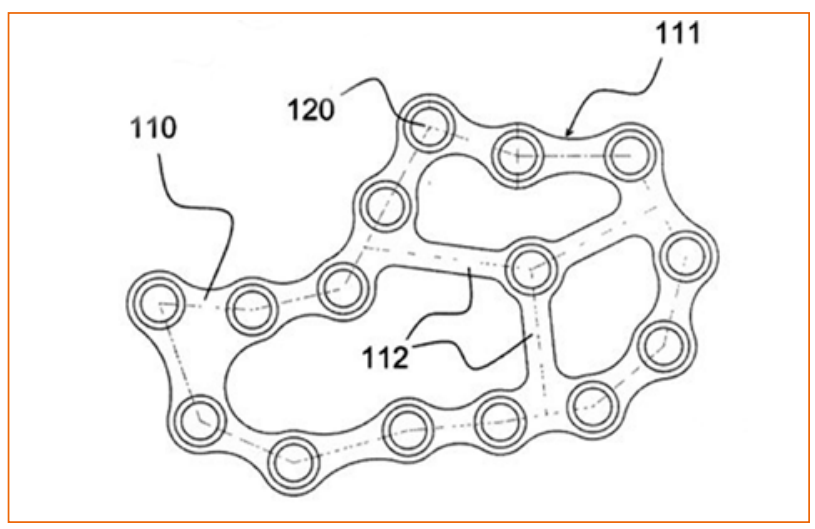

Şekil 4. Dar ebatlı sol topuk kemiği plağının önden görünümü. [1]

Şekil 5'te; Sağ kalkaneus kemik modeli ile sağ ve sol taraf için iki farklı ebatta imal edilmiş plakların önden (dış taraftan) (a) ve perspektif (b) görünümleri verilmiştir.
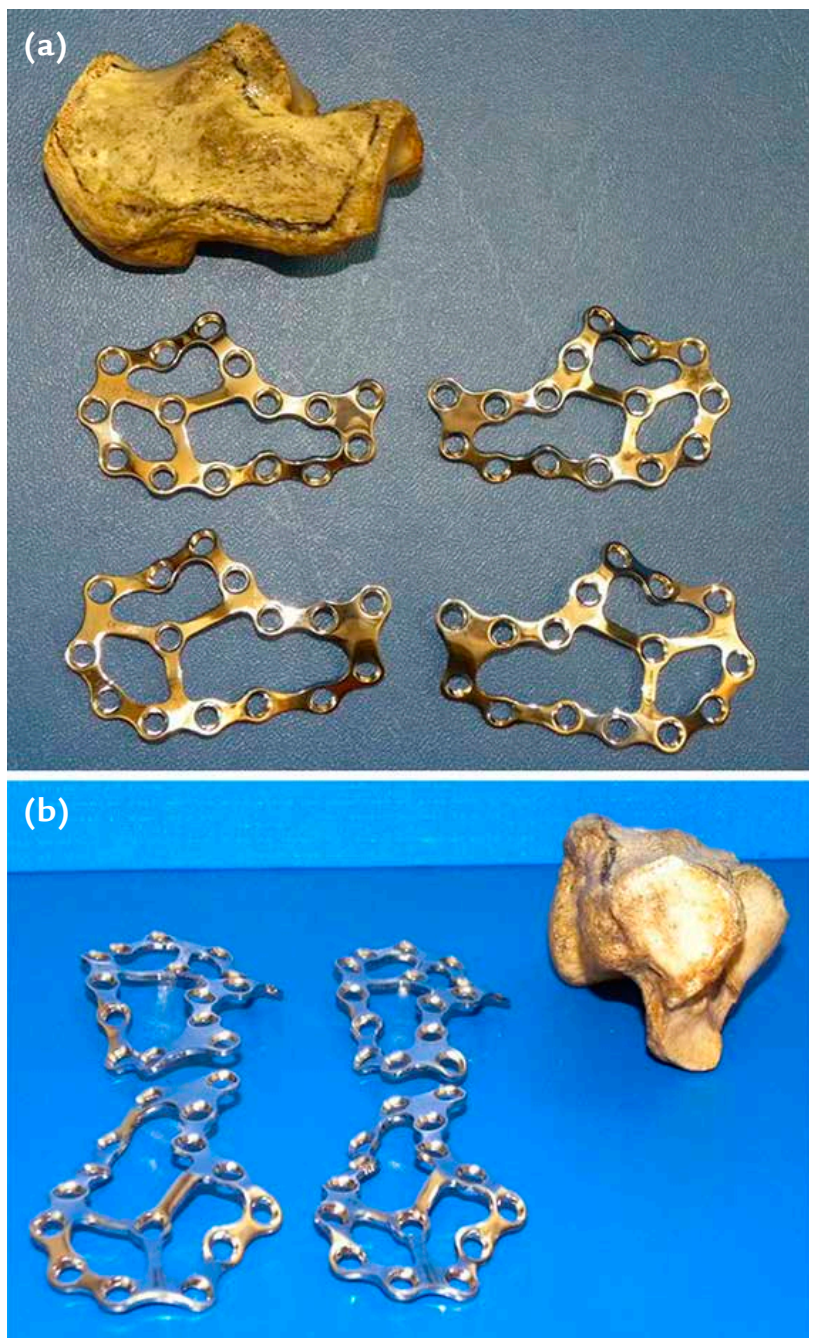

Şekil 5. a, b. Sağ kalkaneus kemik modeli ile sağ ve sol taraf için iki farklı ebatta imal edilmiş plakların önden (dış taraftan) (a) ve perspektif (b) görünümleri.

\section{İstemler ${ }^{[1]}$}

"1. Buluş, tıp alanında ve topuk kemiği (kalkaneus) kaynaklı kırıklarda kullanılmak üzere, sağ ve sol topuk kemiği için ayrı ayrı ve farklı topuk kemikleri için farklı ebatlarda oluşturulan ve topuk kemiğinin dış duvarının anatomik yapısına uyum sağlayacak şekilde girinti, çıkıntı ve eğimlere sahip en az bir gövdeden (110) ve bahsedilen topuk kemiğine sabitlenmesini sağlamak üzere enine açılmış en az bir bağlantı deliğinden (120) meydana gelen topuk kemiği (kalkaneus) plağıdır (100). ${ }^{[1]}$

2. Istem 1'e uygun topuk kemiği plağı (100) olup, bahsedilen gövdenin (110), tek sıra ve seri halde oluşturulan bağlantı deliklerine (120) sahip bir çerçeve (111) ve bunun içinde kalacak şekilde üç kol ile (112) bahsedilen çerçeveye (111) sabitlenen en az bir bağlantı deliği (120) içermesi ile karakterize edilmektedir. ${ }^{[1] "}$

\section{YAZARIN KONUYLA ILGILI ÇALIŞMALARI}

Eklem içi kalkaneus kırıkları genellikle yüksek enerji ile oluşan çok parçalı kırıklardır. Subtalar ekleme ulaşan ayrışmış eklem içi kırıkları cerrahi tedaviden fayda görürler. Genellikle lateral kesiler kullanılır. Eklemin ve kırık hattının yeniden oluşturulması (redüksiyonu) sonrası tespit için geliş̧irilmiş birçok malzeme bulunmaktadır. Kalkaneus dış (lateral) yüzeyinin anatomik yapısına uygun olarak üretim aşamasında şekillendirilen anatomik lateral çerçeve kalkaneus plağı kemiğin dış yüzeyine çok iyi uyum sağlar. Deliklere iyice oturan vidaları ile hastaları rahatsız etmez. Bu nedenle çok ince bir cilde ve hassas bir dolaşıma sahip olan bu bölgede ciltte herhangi bir çıkıntı oluşturmaz ve oluşabilecek nekroz riskini azaltır. Bu ve yukarıda bahsedilen diğer özellikler, anatomik lateral çerçeve kalkaneus plağını diğer tespit materyallerine kıyasla avantajlı hale getirir. ${ }^{[2]}$ Plaklar (yazarın oğlu; Bora Esenkaya) "(Boreska) Kalkaneus Plağı” adı altında üretilmiştir (TIPSAN).

Anatomik lateral çerçeve plak uygulaması ile kalkaneusun üç boyutlu anatomisi tekrardan oluşturularak, genellikle genç ve aktif iş gücü sağlayan hasta grubunda iyi sonuçlar vermekte, hastalar tedavi sonrası önceki işlerine tekrar dönebilmektedirler. ${ }^{[2]}$

\section{KAYNAKLAR}

1. Üretim sırasında anatomik olarak şekillendirilmiş topuk kemiği plağı. T.C. Türk Patent Enstitüsü. Faydalı Model belgesi. No: TR 2010 01325. https://portal.turkpatent.gov. tr/anonim/arastirma/patent/detayli

2. Esenkaya I, Türkmensoy F, Kemah B, Poyanlı OŞ. Surgical treatment of displaced intraarticular calcaneus fractures using anatomical lateral frame plate. Ulus Travma Acil Cerrahi Derg 2018;24:156-61. Crossref 